\title{
El inglés platonico o el latino de todas las mañanas
}

Luis Carlos Abril

\section{I}

D espués, guardó las llaves en el bolsillo derecho. Y salió al sol. Era una mañana de verano, fresca. Encendió el habitual cigarrillo que fumaba durante aquel recorrido. Dio los buenos días a un vecino. Iba con la mirada puesta en la carretera, a lo lejos. Pero el automóvil celeste con matrícula de "Misión Internacional" no aparecía a lo lejos. Empezó a caminar más despacio. Sabía que siempre duraba siete minutos recorriendo las tres cuadras que lo separaban de su casa a la parada del autobús. No se preocupó mucho, después de todo, tarde o temprano, él pasaría a su lado con el automóvil celeste, lo miraría unos segundos, él correspondería a la mirada, y luego, el auto se perdería entre rayas amarillas en el pavimento y rotaciones veloces de las llantas, se lo tragaría la carretera. Entonces, él iría ya a su trabajo tranquilo, como de costumbre.

Una basura cualquiera, o una ráfaga de aire, entró en su ojo. Se detuvo y hurgó, frotándose el ojo con un dedo. El cigarrillo se le cayó. Estuvo a punto de perder el equilibrio al chocar su zapato derecho con una parte de la acera que estaba levantada.
Pero aun así, no quitó la vista de la carretera. Esperaba. Entre más situaciones detuviesen su recorrido, más seguro era encontrarse. Encendió otro cigarrillo. Sintió comezón en la punta de la nariz. Después, se arregló el cuello de la camisa y el nudo de la corbata. Tosió. Pensó que iba a coger la gripe. Mientras tanto, ya había caminado otra cuadra y quedaba sólo la última cuadra. No quiso pensar que sería la última oportunidad ese día. Por la acera del otro lado caminaba el vecino gordo. Pensó que no era tan gordo, sino solamente una incipiente barriga de cincuentón. Ya había ocupado los habituales siete minutos del recorrido diario. No quiso preocuparse por si llegaba tarde. Tendría que verlo esa mañana. No era posible romper la rutina, pues nada había sucedido en el mundo como para que él no pasara por la carretera. Volvió a toser y volvió a pensar que iba a coger la gripe. Le quedaba media cuadra. Un buenos días lo sorprendió pensando que iba a coger la gripe. El vecino había corrido a través de la calle y ahora se hallaba a su lado. Era un hombre que poseía automóvil, así es que recibió de respuesta a su pregunta un "está descompuesto y no estará listo hasta dentro de dos días". Se conocían solo porque trabajaban 
en el mismo edificio, porque se habían encontrado en el café de la esquina y él se había fijado en la compañía femenina de su vecino: una tal Violeta, "que está de lo mejor", como pensaba mientras el café se enfriaba. Sabía que era Gerente de Personal y que su nombre era Manuel. Por lo demás, nunca pasaban de un saludo. Así es que su compañía vino a importunarle. Justo en el momento en que pensaba que su compañía era inoportuna y respondía que no, que no había visto el partido de fútbol del domingo ni el penal fallado, el vehículo celeste con matrícula de "Misión Internacional" apareció en la carretera a dos o tres cuadras de distancia. Sonrió. Luego dijo que sí, que muchas gracias, que sería una buena oportunidad reunirse un día de estos para ver el fútbol dominical. El vehículo estaba ya a una cuadra de llegar a él. Entonces, fue aquí donde respondió que talvez, que talvez sí iba a coger la gripe, y volvió a toser, dando las gracias al vecino por el medicamento que le recetaba. El auto llegaría a él dentro de diez segundos. "No, soy de Saprissa". Ocho segundos.

"Casi nunca le pongo atención al fútbol". “Cinco segundos", pensó. Dos, uno. Pasó a su lado y él sonrió para sus adentros. Dijo que sí, que sería conveniente abordar un taxi. Sonrió esta vez de verdad, dejando mostrar su perfecta dentadura. Lanzó la colilla a la cuneta y corrió detrás del vecino que ya casi subía al taxi. El viento de la mañana pasó cerca de su rostro y se detuvo en un mechón de cabello sobre la frente.

Meses atrás había deducido que él trabajaba en el organismo internacional, kilómetros más allá de su casa, que era extranjero (su cabello rubio, ojos celestes, así lo hacían parecer), y lo llamaba el inglés platónico, aunque sabía que no podía ser de Inglaterra porque en el organismo sólo trabajaban personas de este continente. Pero el nombre le gustó y lo llamaba para sí mismo el inglés platónico. Para sí mismo, porque nadie sabía de aquel ritual de cada mañana, de cada vez que iba o regresaba de su trabajo. Porque también lo veía a la hora de almuerzo; o cuando regresaba de nuevo al trabajo, después del almuerzo; o cuando por la tarde volvía a su casa. Cuatro veces al día y cuatro veces sus miradas se cruzaban, durante cinco días a la semana. Veinte veces por semana se miraban.

No recordaba cuándo empezó a detectar la presencia del automóvil celeste en la carretera; podría ser hace dos semanas, tres meses, un año, talvez desde siempre; lo cierto era que aquel personaje extraño, misterioso, existía; y desde que él salía de su casa iba con la vista al frente, dos o tres cuadras a la distancia.

Vivía en la intriga, como los espías. Vivía en la incertidumbre. Durante el día detenía su labor brevemente y recordaba al señor misterio. Se preguntaba quién era aquel hombre, lleno de misterio; o a qué juego jugaba; se preguntaba si era un juego o qué, y también por qué lo miraba.

La mujer regordeta, joven, con los ojos algo bizcos, pero levemente disimulados por el maquillaje, elegantemente vestida, que trabajaba cuatro o cinco pisos arriba de él, en el mismo edificio, entró. Entró en el justo momento en que él se llevaba el lapicero a la boca, alzaba la cabeza y miraba hacia ningún sitio; es decir, se detenía en su trabajo para recordar al inglés 
platónico. Sonrió, pero no era para la mujer regordeta, sino para sí mismo, pues había algo de placentero en aquella incertidumbre. La mujer se sentó en la salita de espera, casi frente a él y dijo: -Vengo por los documentos de la licitación.

Sonó el teléfono de comunicación interna. "Licitación", pensó. Pero era un pensamiento superfluo, ajeno a la verdad, a él mismo. Porque en el fondo estaba pensando en el inglés platónico y no en documentos de licitación.

-Sí, usted es de "Aire Fresco", pronto la hago pasar- dijo, justo en el momento en que alzaba el auricular. Volvió a pensar en él, mientras llevaba el aparato telefónico hacia su oreja derecha. Volvió a preguntarse a qué juego jugaba. Pero no tuvo tiempo porque hubo de responder.-Aló.

La mujer regordeta acomodó su gordura en el asiento, con un gesto delicado, como para disimularla, y escuchó lo que el joven decía:

-Sí, señor, aquí está. Es una dama. Usted dirá cuándo la hago pasar- dijo a la voz al otro lado del teléfono en tanto la mujer terminaba de acomodarse en su asiento. Se sonrió con él.

-Por favor, que espere unos segundos- le dijo. Miró el reloj, y agregó:-Sólo unos segundos.

La mujer regordeta cruzó una pierna. Buscó una revista de entre las que estaban en una mesita baja, a su lado, "Faltan dos horas y media para la hora del almuerzo", pensó él, justo cuando la mujer estiraba la mano hacia la mesita. "Dos horas y media para que pueda verlo", acabó de pensar mientras la mujer terminaba de llevar su mano con la revista hacia la otra, para abrirla.

-Claro, por supuesto. Esperaré -dijo la mujer, y abrió la revista. Su voz era algo nasal. Él la miró, la miró después de haberse sumergido en su trabajo. La miró por encima de sus anteojos después de haber tomado el ritmo del día y cuando ya había comenzado a sumar la columna de números que tenía delante, sobre el escritorio; después de la habitual pausa de todos los días en que se detenía a pensar unos segundos en el inglés platónico. La mujer sintió la mirada. Sonrió, cerrando la revista para abanicarse, y agregar:

-Hace calor hoy.

Él escuchó la palabra calor justo en el momento en que escribía un tres, un punto, y luego un cinco, en una columna de números contables.

-Disculpe. No le escuché

-Que hace calor hoy.

Volvió a pensar en él. Luego dijo lo que tenía que decir:

-Sí, mucho calor.

Después escribió el cero que le faltaba. Minutos, talvez cinco o seis, pero minutos después la mujer entraba a la oficina donde era esperada. Él se quedó con su pensamiento, a solas, para sí mismo, en secreto.

Semanas después, posiblemente meses después, deambulaba por las calles de la 
ciudad. Cruzó en la esquina de la plaza que está al lado del Teatro Nacional, se detuvo bajo un edificio de veinte pisos. Miró hacia el cielo y no hacia el semáforo que daría luz roja; solo vio la nebulosa soledad de un cielo de invierno color gris, que es casi decir, color de frío y abandono urbano. Cruzó la otra esquina y continuó caminado por la Avenida Central. Llevaba la mirada oprimida y el corazón perdido. La niebla empañaba los cristales de las vitrinas. Escasamente circulaban automóviles. Entonces, su corazón da un salto y se detiene. El automóvil celeste pasó a su lado, en dirección contraria, y dobló en la esquina, perdiéndose en el frío de la noche. Supo que el inglés platónico lo reconoció. Tuvo la intención de detenerse. Tuvo la intención de detenerse para siempre en ese justo momento de alegre sorpresa, para dejar de estar como solía: en la incertidumbre, como los espías. Tuvo la impresión de que el inglés platónico hizo el intento de detenerse. Apresura el paso, para dar vuelta alrededor de la cuadra. Apresura la ansiedad, apresura el cigarrillo que está encendido, para calmar la alegría. De acuerdo con la ruta que él llevaba y con la disposición vial de San José, tendrían que coincidir en la esquina en donde suponía que coincidirían. Dobló en la primera esquina, y continuó caminado con los pasos vestidos de velocidad. Llega la segunda esquina, dobla, pero no se produce ningún encuentro.

Justamente hoy en la mañana, se dijo: "Hoy lo detendré y aclararé todo este juego del misterio". Pero no pudo en ninguna de las cuatro ocasiones en que se encontraron porque el vecino tenía otra vez el auto descompuesto, lo que implicó que el vecino lo acompañó a la parada del autobús durante esas cuatro, y aburridas, ocasiones.

Ahora la cerilla se apaga y no logra encender el cigarrillo. Se aclara la tensión y trata de calmar la voz para las palabras que le dirá. Suelta el humo y el humo se pierde más allá de la noche, entre la niebla y la llovizna. Lleva la nariz fría, el cabello cubierto de finas gotitas de lluvia, que también cuelgan en su suéter de lana, la respiración apresurada. Está a punto de llegar a la tercera esquina, empuja a un hombre que se cruza con sus pasos. No pide disculpas. Pero pensó una frase obscena. Llega a la esquina: a la derecha se ve únicamente el silencio del invierno, la humedad del pavimento, y a media cuadra, una mujer que camina hacia él; a la izquierda no se ve nada, excepto otra vez el invierno en su traje de frío. El automóvil celeste no pasó nunca. Es imposible no haber coincidido, de acuerdo con la ruta que llevaba y de acuerdo con las vías del tránsito. Pero no hubo ningún encuentro en esa tercera esquina.

Empezó a caminar hacia la cuadra por donde caminaba al principio.

-Mañana lo detendré- se dijo en voz alta. La mujer pasó a su lado. Vuelve a verlo con gesto de asombro. Cruza la calle, asustada.

Vivía en el país de la zozobra. Su vida se había convertido en un deseo incontrolable por aclarar aquella situación, por dejar de jugar al misterio. Día tras día, hora tras hora, el inglés platónico ocupaba su pensamiento, sus actos, su forma de respirar. "Sí, porque en algún momento de nuestra 
vida el ser más desconocido puede convertirse en el eje más importante de nuestra rutinaria existencia", pensaba aquella mañana en que iba recordando la noche anterior en la ciudad. El inglés platónico era una imagen fija en su mente: la imagen del caballero del misterio de la rutina de cada día. Esta mañana está decidido a descorrer el velo del juego misterioso.

Pero el inglés platónico no pasó esa mañana. Ni tampoco a mediodía ni por la tarde. Algo debió suceder. En todos estos meses nunca ha dejado de pasar. No puede la costumbre romperse en una sola mañana. Y no puedo yo quedarme con las manos vacías. No he perdido el sueño durante tantas y tantas noches ni mi concentración en cada uno de mis actos, como para quedarme ahora con las manos vacías", pensaba, parado junto a un autobús que no iba a abordar, y mientras habían transcurrido los habituales siete minutos, mientras habían transcurrido inhabituales veinte minutos, mientras el vecino gordo con el auto descompuesto no había coincidido con él, mientras el humo del tercer cigarrillo se fugaba en el frío aire de octubre.

"En algún sitio de la vida, en alguna esquina del destino, he de encontrarlo", pensó, media hora después, cuando ya subía al autobús.

Pero pasó un año. Cada paso que daba era un paso de alerta roja por descubrirlo en algún lugar; cada paso era el paso del sigiloso cazador tras la presa.

"Ahora, cuando en las mañanas voy hacia el trabajo, miro hacia el frente, hacia donde está el vacío. Sé que algo falta siempre: el automóvil celeste. Pero esto de mirar hacia lo lejos es ya costumbre. Llega un momento en que la costumbre deja de ser algo tedioso para convertirse en el placer de darle sentido a la vida. Un año y no volví a verlo. Ya no importa tanto, como al principio, el vacío. Lo importante es no romper la rutina, el rito. Guardo muy bien la ritual costumbre de mirar siempre hacia ese vacío en la carretera".

\section{II}

No voy a firmar todavía toda esta gran cantidad de documentos. No tengo deseos. Prefiero mirar hacia ningún sitio, y recordarlo. Ya se ha hecho costumbre detenerme en mi labor del día para recordar a ese joven misterio. Y también se ha hecho rutina preguntarme a qué juego está jugando. Dijo sí, que pronto. Se lo dijo a mi secretaria que entró sin previo aviso a preguntarme si le daría la tarde de mañana libre. Pero es un sí como si no hubiese sido pronunciado por mí, sino por otro que está aquí, porque el verdadero está a mil distancias de lejanía. Aquí, una fastuosa oficina con paredes de madera de color natural, amplios sillones blancos, un escritorio de cristal, silla giratoria, estantes con libros, un pequeño bar al lado derecho, y al izquierdo un acuario. Ahora veo cómo la falda rosada de mi secretaria se mueve al compás de sus pasos que se alejan. Aquí estoy, intentando descifrar el misterio de todos los días, cada vez que vengo por la carretera hacia mi trabajo, o voy de regreso hacia mi casa. Mi secretaria se volvió hacia mí, preguntándome algo que no logré captar, porque justo en ese momento, me preguntaba otra vez a qué juego juega el joven misterio. Ahora me escucho decir un "dentro de un rato, aún no", que le 
contesté desde lo más hondo de mi distracción, al preguntarme ella si ya había terminado de revisar estos documentos. Lo preguntó cuando me llevaba esta pluma de plata a la boca y la entretenía entre mis dientes. Sí, creo que lo hace; sí, es cierto, ha sonreído.

Fue después de que lo he hecho; me refiero a que después de que ella cerró la puerta que me incorporé del escritorio, y ahora estoy dando pasos alrededor de la oficina, pensando nuevamente en él. Mis pasos se confunden en un abrazo de suavidad con la alfombra azul. Miro la punta de mis zapatos. Pero nada de esto tiene importancia, son actos realizados por el que está aquí y que a la vez no está porque no tiene conciencia de lo que hace, sino sólo un pensamiento fijo: él.

\section{III}

-Nuestro hermano menor se accidentó en su motocicleta anoche. Ha muerto. Y también su novia. Tan sólo tenían una semana de estar prometidos - dijo mi secretaria, llorando y refugiándose en mis brazos. La consolé con las palabras habituales para una ocasión así, mientras le acariciaba el cabello.

Esa información la recibí hace dos semanas, y después yo recibiría la fatídica llamada que me informaba a mí con lo sucedido a mi hija, que desde la noche anterior había desaparecido. Después del entierro de mi hija, hacia las tres de la tarde, me dirigí al funeral del hermano de mi secretaria. Yo lo vería allí. Lo reconocería dentro del ataúd. Nunca imaginé asociar el apellido de mi secretaria con el nombre del joven que dio mi hija, cuando nos informó que su novio nos visitaría para la petición formal. Esto sucedió un día antes de que mi secretaria me informara de lo de su hermano. Pero el joven no pudo llegar debido a un desperfecto de su moto, camino a casa. Mi hija salió a su encuentro, y de camino otra vez a nuestra casa, sucedió el accidente. Hace dos semanas y un día que los enterramos a los dos. Pero no sabría hasta que me presentara ante mi secretaria para el pésame de rigor. No lo sabría porque tuve que ocuparme del funeral de mi hija. Ya han pasado dos semanas y un día desde que el dolor taladró mi vida.

Yo lo vería en el funeral. Lo reconocería dentro del ataúd. Era él. El novio de mi hija era él: el latino de todas las mañanas, como lo llamaba yo.

Nunca conté a nadie lo que sucedía porque a fin de cuentas no sucedía nada, excepto mirarnos. Ahora mi hija está muerta, ahora el latino de todas las mañanas está muerto, y debo contarme a mí mismo la historia porque el recuerdo es una forma de revivir a los muertos, de mantenerlos vivos y hacerlos parte de nuestra costumbre: el pasado es una forma de la costumbre, de la rutina del diario vivir.

Aquella noche fue la última vez que lo vi. Intenté localizarlo, conduciendo por donde suponía que él iría caminando. Pero fue en vano. El latino de todas las mañanas no apareció entre las húmedas calles, tal vez se escondió detrás de la niebla o un poco más allá del frío. Pero antes de ello, cuando lo vi, mi corazón dio un salto. Y se detuvo. Fue la última vez. Hace exactamente dos años y dos semanas con un día. Aquella noche yo cumplí años. Después, pasado 
un año desde aquella noche, ya ni siquiera me acordaba de él, ya no me detenía en mi trabajo y pensaba en él, en el misterio de cada mañana. Hoy también cumplo años. Y debo recordar esta vez para no olvidar nunca jamás aquel ritual de la costumbre. Qué tarde nos avisa el tiempo de que la oportunidad de romper el muro del silencio ha pasado, de romper la indiferencia que nos identifica a todos y saltarnos de la costumbre del diario vivir y penetrar en territorios desconocidos, en los territorios de los demás.

Nunca sabré por qué me miraba. Era un juego ritual. Y hasta me divertía, después de verlo pasar, con la cantidad de interrogantes que me asaltaban. Existía, sí, existía. Cada mañana existía, como también existe el sol, el aire, la sonrisa de un niño, es decir, el mundo continuaba normalmente su marcha. No habíamos sido carbonizados durante la noche por los cohetes, ni éramos espectros cenicientos viviendo sin motivo alguno después de una hecatombe nuclear. Ni éramos cadáveres entre escombros porque no hubo un terremoto durante la noche. Ni un cuerpo asesinado por bandoleros que entraron a la casa a robar. No. Éramos seres humanos inmersos en el gran engranaje del diario vivir. Encontrarlo cada mañana me aseguraba que yo era un canadiense, que trabajaba en un organismo internacional, unos tres kilómetros más allá de donde siempre lo encontraba; que estaba vivo, aún vivo, continuando con la rutina de la vida.

Ahora él está muerto.

El ritual y el juego se convirtieron en una forma de hacer soportable el viaje de diez kilómetros hacia mi trabajo. Algunas veces tenía la leve impresión de que detenía su marcha hasta verme aparecer en la carretera. Sé que distinguía mi automóvil por su matrícula amarilla de "Misión Internacional". Y también yo hacía lo mismo: detener la velocidad del carro, hasta verlo pasar por la acera.

No recuerdo cuándo empecé a detectar la presencia del latino de todas las mañanas. Pudo haber sido después de dos semanas de trabajar en el organismo, después de meses, o una estación, un año, talvez desde siempre. Talvez siempre estuvo haciendo ese recorrido de dos o tres cuadras desde su casa hasta la parada del autobús, porque talvez ese era su destino: recorrer siempre el mismo espacio, para no alterar las leyes de la costumbre; talvez esa distancia era el limbo, y su mirada era un desgarrador ruego para que yo lo rescatara del limbo, talvez siempre estuvo preso en esa distancia para cumplir su ritual de eterno gitano errante.

Ahora pienso que el limbo es la vida de todos los días.

Solo sé que un día ya nos mirábamos. Siempre me preguntaba quién era aquel muchacho, o a qué juego jugaba, o si era un juego o qué. Todas estas preguntas me las hacía mientras iba camino al trabajo. Estuve tentado en más de una ocasión a detenerme y preguntarle. Pero también corría el riesgo de que la magia se rompiera, la magia de la costumbre diaria. Porque había magia en aquel juego ritual. Era una forma de vivir y de escapar del tedio. Era una forma de ofrendar a la rutina. Algunas veces me detenía en el trabajo unos 
segundos y los dedicaba a recordar al muchacho misterio.

Recuerdo que una vez, estando en el vestíbulo de un cine con mi hija, la pillé coqueteando con un joven. Yo estaba de frente hacia ella, dando la espalda al joven. Me volví en el justo instante en que el joven se daba la vuelta y nos quedaba de espal$\mathrm{da}$, de manera que no pude verle el rostro. Para mí fue simple curiosidad. Pasarían muchos hasta que descubriría quién fue el joven aquel. Era él: el latino de todas las mañanas, el que ahora está muerto. Mi hija me dijo un día:

-Hoy saldré con aquel muchacho que vimos en el cine, cuando fuimos a ver aquella película rock que no te gustó. Talvez terminemos de novios.

Y lo fueron. Ahora ambos están muertos. Y debo recordar, recordar que aquella noche fue la última noche que lo vi con vida. Yo había salido a tomar una copa para celebrar mi traslado a las oficinas centrales, en el centro de la ciudad. Detestaba viajar todas las mañanas a las afueras de la ciudad (lo único que hacía soportable el viaje era encontrarlo a él). Hacía frío y había niebla. El tráfico era casi inexistente. El viento hacía que las gotitas de lluvia en el parabrisas se deslizaran suavemente hacia abajo, como acariciando el vidrio. Iba por la avenida central. Mi corazón dio un salto. Y se detuvo. Pero no podía detener el vehículo en plena calle. Tuve la leve impresión de que él también me reconoció. No, tuvo que reconocerme, no cabía la menor duda porque siempre, día a día, nos encontrábamos. Sí, sé que él me reconoció. Conduje por las calles por donde suponía que tendría que caminar, recorro la primera cuadra. Llego a la esquina. Luz roja. Vuelvo a doblar a la izquierda. Llego a la esquina en donde supongo que lo encontraré. Veo hacia la derecha: únicamente se ve el silencio del invierno, la humedad del pavimento; a la izquierda tampoco hay nada, excepto otra vez el invierno en su traje de frío. El latino de todas las mañanas no pasó nunca.

-Mañana lo detendré- me dije, mientras hacía un alto en la esquina, y mientras una mujer que detenía su auto junto al mío, sonreía al verme hablar solo.

A la mañana siguiente, el trabajo de todos los días, el detenerse un instante, un mínimo segundo y pensar en el muchacho misterio. La rutina de siempre: el buenos días de siempre a la secretaria de siempre, a los subalternos, el café de siempre a las nueve, a las tres de siempre, el hasta mañana de siempre, ahogante. El limbo de siempre, el limbo de la vida de siempre.

Sí, esa noche lo vi, la noche de mi cumpleaños. El director del organismo me había agasajado con mi traslado, como regalo, a las oficinas en el centro de San José, y había salido a tomar una copa para celebrarlo. Entonces me dije que a la mañana siguiente. Pero lo había olvidado: era tal la rutina. Había olvidado que nunca más volví a ver al latino de todas las mañanas. Nunca sabré por qué me miraba.

Ahora él está muerto. Se llevó para siempre la respuesta. 

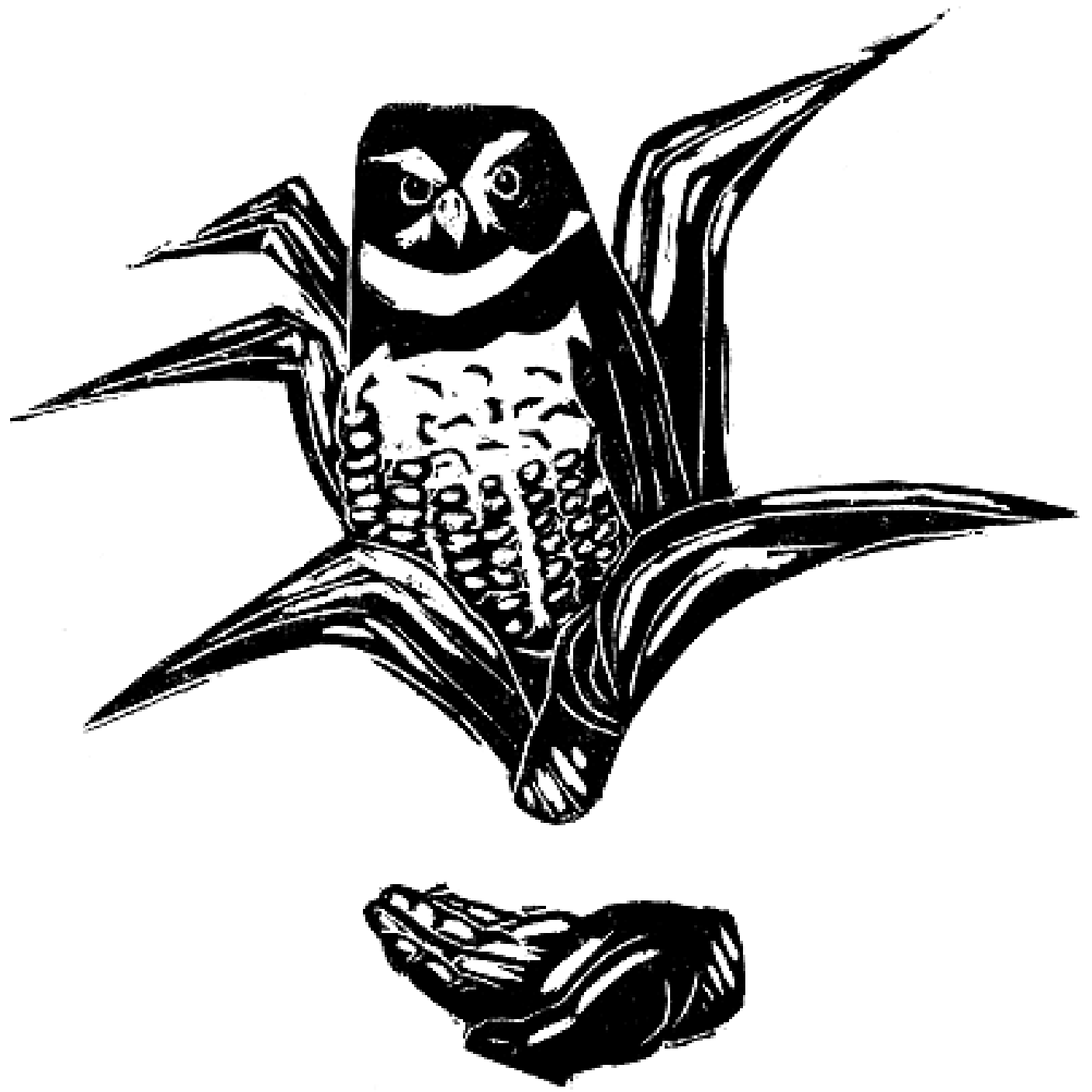

Juan Carlos Zuñiga Villalobos

Vigilante

Xilografia

$25 \times 30 \mathrm{~cm}$

2017 